\title{
Addendum: Editorial note: Lethal H5N1 influenza viruses escape host anti- viral cytokine responses
}

\author{
Sang Heui Seo, Erich Hoffmann \& Robert G Webster \\ Nat. Med. 8, 950-954 (2002); published online 26 August 2002; addendum published after print 5 October 2012
}

The above paper originally reported that H5N1 viruses are resistant to interferon in the SJPL cell line. The editors wish to alert our readers about three facts that may affect this conclusion. First, Ngunjiri et al. (Nat. Med. 18, 1456-1457, 2012) have recently found that aliquots of the SJPL cell line obtained from the American Type Culture Collection were heavily contaminated with mycoplasma. Although the mycoplasma status of the cells used in the original paper is unknown, it is not possible to rule out that they were contaminated. Second, SJPL cells were originally reported to be of porcine origin, but a recent analysis (Silversides, D.W. et al. J. Virol. 84, 5454-5455, 2010) has indicated that they are of simian origin. Third, Ngunjiri et al. have found $\mathrm{H} 5 \mathrm{~N} 1$ viruses to be sensitive to interferons in all cell lines tested from multiple species.

\section{Corrigendum: Potent inhibition of heterotopic ossification by nuclear retinoic acid receptor- $\gamma$ agonists}

Kengo Shimono, Wei-en Tung, Christine Macolino, Amber Hsu-Tsai Chi, Johanna H Didizian, Christina Mundy, Roshantha A Chandraratna, Yuji Mishina, Motomi Enomoto-Iwamoto, Maurizio Pacifici \& Masahiro Iwamoto Nat. Med. 17, 454-460 (2012); published online 3 April 2011; corrected after print 5 October 2012

In the version of this article initially published, the authors inadvertently used a-tubulin normalization data in the western blots shown in Figure $4 \mathrm{~b}$ and Figure $4 \mathrm{e}$ from separate experiments used to generate the other bands shown. The error did not affect the main conclusions of the paper. Nonetheless, to verify the data, the authors have repeated the experiments, and the data from one such experiment are now included for both these figure panels. The authors regret the occurrence and apologize for it. The error has been corrected in the HTML and PDF versions of the article.

\section{Corrigendum: Multigenerational epigenetic adaptation of the hepatic wound- healing response}

\begin{abstract}
Müjdat Zeybel, Timothy Hardy, Yi K Wong, John C Mathers, Christopher R Fox, Agata Gackowska, Fiona Oakley, Alastair D Burt, Caroline L Wilson, Quentin M Anstee, Matt J Barter, Steven Masson, Ahmed M Elsharkawy, Derek A Mann \& Jelena Mann Nat. Med. 18, 1369-1377 (2012); published online 2 September 2012; corrected after print 5 October 2012

In the version of this article initially published, in Figure $6 \mathrm{f}$ the left-hand graph was an inadvertent duplication of the right-hand graph. The error does not alter the overall conclusions of the paper. The figure has been corrected in the HTML and PDF versions of the article.
\end{abstract}

